\title{
PENDAMPINGAN PENGGUNAAN MEDIA PEMBELAJARAN BERBASIS KIT IPA UNTUK PEMBELAJARAN FISIKA DI SMPN 2 SEKOTONG
}

\author{
Rahadi Wirawan'1), Nurul Qomariyah'1), Suhayat Minardi1), \\ Syamsuddin'1), Hiden ${ }^{1)}$, Wayan Sudiarta ${ }^{1)}$, Marzuki') \\ 1)Program Studi Fisika, Fakultas Matematika dan Ilmu Pengetahuan Alam, Universitas Mataram, Mataram, \\ NTB, Indonesia \\ Corresponding author : Rahadi Wirawan \\ E-mail : rwirawan@unram.ac.id
}

Diterima 10 April 2021, Disetujui 15 April 2021

\begin{abstract}
ABSTRAK
Kegiatan pengabdian kepada masyarakat ini dilakukan guna meningkatkan kemampuan penggunaan dan pemanfaatan set eksperimen Komponen Instrumen Terpadu (KIT) IPA untuk penggalian konsepkonsep dasar Fisika siswa melalui pembelajaran berbasis eksperimen. Kegiatan pengabdian dilaksanakan di SMPN 2 Sekotong Kabupaten Lombok Barat, dengan peserta guru-guru Fisika dan siswa-siswa kelas 8 . Metode yang digunakan dalam kegiatan ini adalah direct instruction, cooperative learning dan diskusi. Adapun set eksperimen yang digunakan adalah KIT IPA untuk materi Mekanika, Panas dan Hidrostatistika, Optik, dan Listrik Magnet. Pada kegiatan ini peserta memperoleh pengetahuan tentang metode pembelajaran berbasis eksperimen dan keterampilan merakit serta memodifikasi KIT IPA yang dapat digunakan untuk mendukung pembelajaran Sains. Dengan demikian, pembelajaran Sains akan menjadi pembelajaran yang menyenangkan dan diharapkan meningkatkan minat dan prestasi belajar siswa.
\end{abstract}

Kata kunci: KIT; konsep fisika; eksperimen; ketrampilan; minat belajar.

\begin{abstract}
This community service activity is carried out to improve the ability to use the IPA Integrated Instrument Components (IIC) experimental set to explore the student basic concepts of physics through experimentbased learning. This activity was carried out at SMPN 2 Sekotong West Lombok Regency with participants from physics teachers and 8th-grade students. The method that used is direct instruction, cooperative learning and discussion. The experimental set used is the IPA IIC for the materials of Mechanics, Heat and Hydrostatic, Optics, and Magnetic Electricity. In this activity, participants gain knowledge about experimental based learning methods and skills of assembling and modifying science KITs that can be used to support science learning. Thus, science learning will be fun learning and it is expected to increase student interest and learning achievement.
\end{abstract}

Keywords: IIC; physics concept; experiment; skills; learning interest.

\section{PENDAHULUAN}

Pembelajaran Fisika di sekolahsekolah kurang begitu disukai siswa dan dianggap sebagai pembelajaran yang sulit. Hal ini disebabkan kurangnya ketertarikan siswa untuk belajar Sains khususnya bidang Fisika. Selaras dengan hal tersebut, guru belum sepenuhnya melibatkan proses Sains dalam pembelajaran dan masih menerapkan metode pembelajaran konvensional yang berorientasi pada guru sebagai pusat belajar (teachercentered) dengan metode penyampaian materi dan latihan soal sehingga dirasa sangat membosankan (Suparno, 2007). Seperti diketahui bahwa pembelajaran Fisika yang merupakan salah satu ilmu dasar membutuhkan penanaman konsep Fisika secara utuh dengan memberikan konsepkonsep dasar yang tepat sejak dini khususnya di sekolah-sekolah. Untuk memperoleh hasil pembelajaran Fisika yang optimal, pemilihan metode yang tepat dan media pembelajaran yang sesuai dengan materi yang ingin disampaikan harus menjadi perhatian utama guru. Pembelajaran yang diterapkan mampu melatih dan meningkatkan creativity and innovation, critical thinking and problem solving, communication, collaboration (Saputri dkk., 2017; Oktalia dkk., 2018). Salah satu metode pembelajaran Fisika yang dapat aplikasikan adalah melakukan eksperimen atau demonstrasi menggunakan bantuan alat peraga (Arsyad, 2006). Metode pembelajaran tersebut lebih menekankan siswa pada 
ketrampilan proses dan pengalaman belajar yang dapat terekam dengan baik oleh siswa dan dapat meningkatkan hasil belajar kognitif (Subekti dan Ariswan, 2016). Sementara itu, penggunaan alat peraga sebagai media pembelajaran dimanfaatkan untuk mengkomunikasikan materi yang diajarkan kepada peserta didik (Murphy, 2006). Permasalahan yang sering dijumpai dan dihadapi guru pada penerapan metode eksperimen atau demontrasi tersebut adalah kurangnya ketersediaan sarana alat-alat praktek/peraga penunjang pembelajaran dan minimnya penguasaan menggunakan alat peraga yang ada di sekolah-sekolah.

Komponen Instrumen Terpadu IImu Pengetahuan Alam (KIT IPA) merupakan suatu kotak yang berisi sekumpulan alat-alat yang dirancang dan dibuat menyerupai rangkaian peralatan ujicoba ketrampilan proses bidang studi IPA dan dilengkapi dengan buku petunjuk penggunaannya (Pamungkasih dan Pusporini, 2018), digunakan untuk suatu tujuan pembelajaran tertentu seperti halnya penggunaan KIT mekanik untuk pokok bahasan Hukum Newton, KIT Listrik dan Magnet untuk pembahasan terkait dengan kelistrikan dan kemagnetan. Pemanfaatan KIT IPA sampai saat ini masih belum maksimal dalam meningkatkan ketrampilan peserta didik (Payu dkk., 2015).

SMPN 2 Sekotong merupakan salah satu sekolah menengah pertama yang berada di wilayah Kabupaten Lombok Barat bagian selatan yang termasuk dalam katagori wilayah terluar dengan jarak sekitar $60 \mathrm{~km}$ dari kota Mataram. Observasi awal keberadaan peralatan laboratorium IPA di sekolah tersebut menunjukkan bahwa penanganan dan pemanfaatan peralatan-peralatan laboratorium belum dilakukan secara baik dan optimal. Belum adanya laboran atau guru yang diberikan tanggungjawab mengelola laboratorium dan mengembangkan pemanfaatan media pembelajaran KIT IPA untuk mendukung kegiatan belajar mengajar. Beberapa fakta yang diperoleh terkait dengan keberadaan dan pengunaan KIT IPA antara lain: (1) di sekolah terdapat KIT IPA lengkap, akan tetapi para guru tidak bisa menggunakannya, (2) guru-guru IPA masih bingung mencocokkan antara materi ajar dengan alat peraga atau KIT IPA yang akan digunakan, akibatnya pembelajaran IPA yang seharusnya student centered dan kontekstual hanya diajarkan tekstual saja, (3) belum ada upaya pembekalan atau pelatihan perancangan media pembelajaran mandiri baik oleh Lembaga Penjamin Mutu Pendidikan (LPMP) ataupun lembaga-lembaga pendidikan lainnya, sementara kompetensi tersebut sangat diperlukan dan dimiliki oleh para guru.

Beberapa permasalahan telah dipaparkan di atas mendorong kami selaku tim pengabdian kepada masyarakat dari Program Studi Fisika, Fakultas Matematika dan IImu Pengetahuan Alam (FMIPA) Universitas Mataram melakukan kegiatan pendampingan 2M (Merakit dan Memodifikasi) KIT IPA untuk Pembelajaran Fisika Berbasis Eksperimen di SMPN 2 Sekotong Kabupaten Lombok Barat. Kegiatan ini sebagai salah satu upaya untuk meningkatkan kemampuan para guru terkait dalam meningkatkan kemampuan merancang dan memodifikasi media Pembelajaran KIT IPA.

\section{METODE}

Metode yang digunakan dalam kegiatan ini adalah direct instruction, cooperative learning dan diskusi. Metode direct instruction digunakan untuk penyampaian materi ajar yang dapat dirancang dan dimodifikasi berdasarkan KIT IPA yang tersedia yaitu kit mekanika, kit optik, kit listrik dan magnet, kit panas dan hidrostatika, serta alat umum Fisika. Metode cooperative learning dan diskusi digunakan pada saat pelatihan perakitan media pembelajaran berbasis KIT IPA pada peserta workshop. Hal ini dimaksudkan agar pemahaman konsep Fisika yang dicapai peserta workshop terstruktur dan utuh. Untuk memecahkan permasalahan yang telah disebutkan di atas, telah dilakukan realisasi pemecahan masalah sebagai berikut: (1) mengenalkan suatu metode pembelajaran Fisika yang sesuai dengan konsep konstruktivisme yang menekankan pada learn to do yaitu pembelajaran Fisika menggunakan metode eksperimen berbasis KIT IPA. (2) memberikan pelatihan perakitan KIT IPA untuk meningkatkan efektivitas KIT IPA pada pembelajaran Sains. Pada setiap tahapan yang dirancang peserta dituntut untuk aktif agar mendapatkan hasil yang optimal.

\section{HASIL DAN PEMBAHASAN}

Pelaksanaan kegiatan pengabdian pendampingan penggunaan KIT IPA dilakukan dalam beberapa tahapan kegiatan untuk mendapatkan hasil yang optimal. Kegiatan tersebut terbagi dalam 3 kegiatan pokok yaitu:

\section{Pendalaman konsep dasar IPA}

Tampak pada Gambar 1, salah satu anggota tim pengabdian sebagai narasumber menjelaskan konsep-konsep pembelajaran Sains berbasis metode eksperimen dan konsep-konsep dasar Matemtika dan IPA khususnya pada materi-materi Fisika. Konsep dasar Fisika yang diberikan adalah materi dasar 
yang sesuai dengan alat-alat KIT IPA yang terdapat di sekolah SMPN 2 Sekotong, sehingga diharapkan peserta dapat mengoptimalkan penggunaan KIT IPA. Pembelajaran berbasis eksperimen adalah pembelajaran yang menggunakan alat peraga sebagai media pembelajaran guna memudahkan siswa untuk memahami konsep materi yang diajarkan. Alat-alat peraga yang disediakan dalam kotak KIT IPA tersebut terkait dengan materi-materi Mekanika, Optik, Listrik dan Magnet, Panas dan Hidrostatika serta alatalat ukur besaran Fisika.

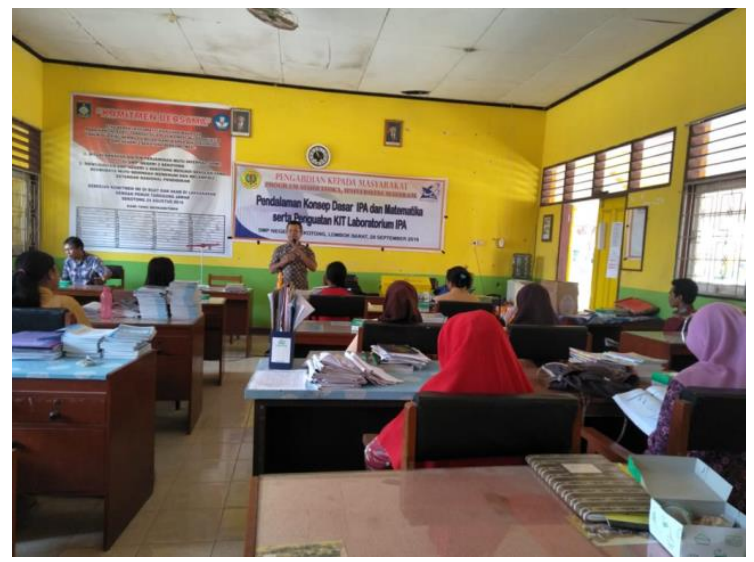

(a)

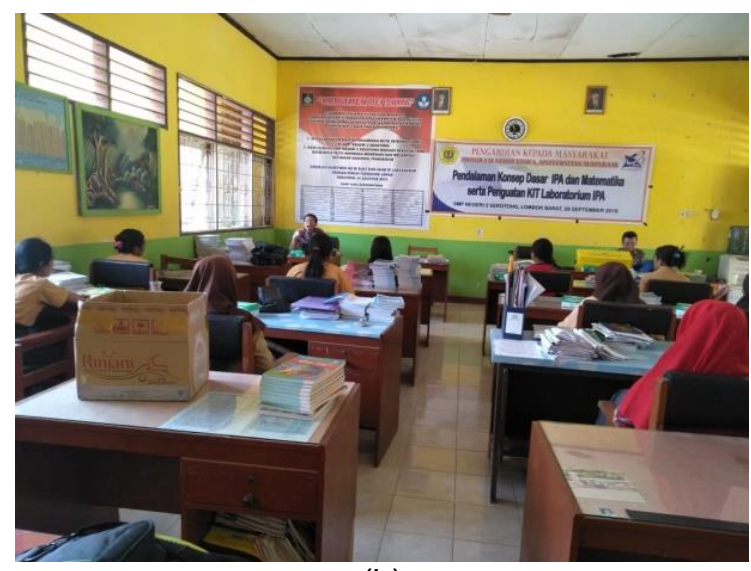

(b)

Gambar 1. Penyampaian materi (a) Konsep pembelajaran eksperimen, (b) Konsep dasar Matematika dan IPA

\section{Demonstrasi Perakitan KIT IPA}

Pada tahapan ini tim pengabdian mendemonstrasikan cara penggunaan dasar KIT IPA berdasarkan modul yang telah dibuat; tahapan ini dilakukan dengan tujuan memberikan pengetahuan tentang nama dan fungsi alat. Pada tahapan ini ditekankan bahwa set KIT IPA merupakan alat peraga yang dapat digunakan baik sesuai modul ataupun keperluan eksperimen materi lain yang dibutuhkan. Dengan penggunaan KIT IPA pemahaman konsep dasar Fisika lebih mudah untuk disampaikan karena peserta didik melihat langsung gejala fisis yang terjadi. Pada Gambar 2 terlihat tim pengabdian sedang mendemonstrasikan KIT Mekanika yaitu pegas.

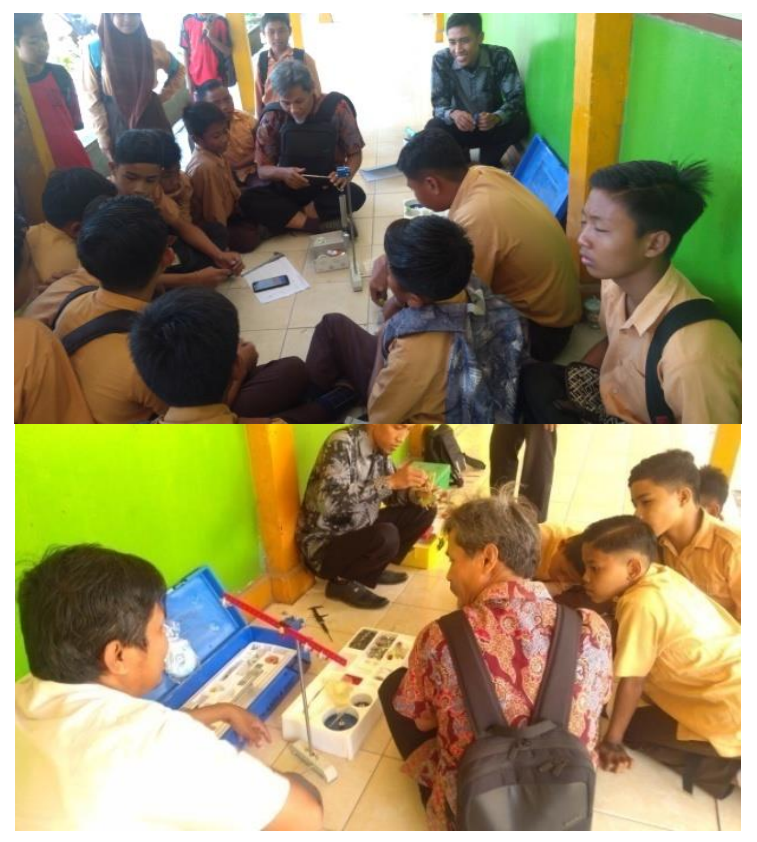

Gambar 2. Demonstrasi perakitan KIT Mekanika

\section{Simulasi Perakitan KIT IPA oleh Peserta}

Peserta diberikan projek sederhana untuk mensimulasikan langsung tentang eksperimen yang dapat dilakukan menggunakan alat-alat yang ada pada masingmasing Kit IPA dan disesuaikan dengan kurikulum/materi ajar (Gambar 3). Kegiatan ini mampu meningkatkan motivasi siswa dalam belajar Sains. Selain itu juga dapat memberikan pengetahuan kepada peserta didik tentang alat KIT IPA dan cara penggunaannya dalam pembelajaran.

Selanjutnya pada kegiatan simulasi penggunaan KIT tim juga merangsang peserta untuk momodifikasi penggunaan KIT sebagai set eksperimen yang dapat disesuaikan dengan materi sesuai kebutuhan sehingga penggunaannya lebih optimal. Dengan simulasi ini, siswa-siswa mendapatkan pengalaman langsung dalam mensimulasikan KIT IPA sehingga dapat diaplikasikan pada pembelajaran Sains di sekolah mereka. 


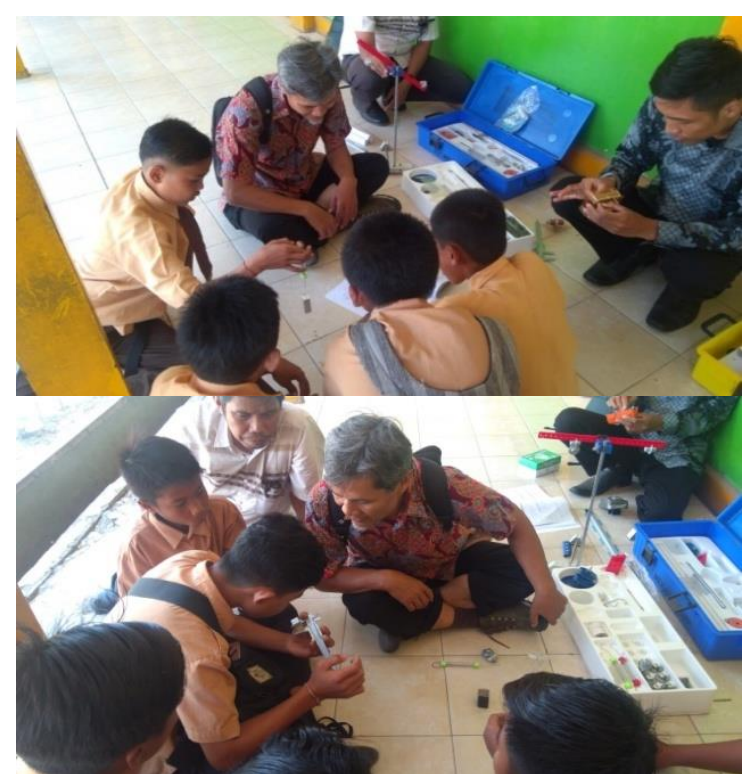

Gambar 3. Pendampingan simulasi pembelajaran menggunakan KIT IPA

\section{SIMPULAN DAN SARAN}

Kegiatan ini dapat memberikan manfaat kepada peserta yang terdiri dari guruguru Sains serta siswa-siswa berprestasi SMPN 2 Sekotong Kabupaten Lombok Barat, yaitu dapat memberikan pengetahuan tentang pembelajaran menggunakan metode eksperimen, mengoptimalkan penggunaan alat peraga KIT IPA dalam pembelajaran Fisika berbasis eksperimen sehingga penggalian dan penanaman konsep Fisika dapat dioptimalkan. Peserta juga mampu merakit dan memodifikasi KIT IPA untuk mendukung pembelajaran Sains, karena penggunaannya dapat memperlihatkan gejala Fisika pada materi yang diajarkan. Dengan demikian, pembelajaran Sains akan menjadi pembelajaran yang menyenangkan dan diharapkan meningkatkan minat serta prestasi belajar siswa.

\section{UCAPAN TERIMAKASIH}

Kami mengucapkan terima kasih kepada SMPN 2 Sekotong Kabupaten Lombok Barat atas kesediaannya sebagai tempat pelaksanaan kegiatan pengabdian ini.

\section{DAFTAR RUJUKAN}

Arsyad, A. (2006). Media Pembelajaran. Jakarta: Rineka Cipta.

Murphy, (2006), The Impact of ICT on Primary Science, New York: Open University Press.

Oktalia, R., Wijayanti, A., \& Ernawati, T. (2018). Everyone Is $A$ Teacher Here Effect on Science Learning Achievement Based on Critical Thinking Skills. Jurnal IImiah Pendidikan MIPA, 8(3).193-202. http://dx.doi.org/10.30998/formatif.v8i3 .2797

Payu, Citron dan Zainuru, Ahmad. (2015). Pelatihan KIT IPA Guru-Guru Sekolah Dasar di Kecamatan Kwandang Kab. Gorontalo Utara.

Pamungkasih, W. dan Pusporini, W. (2018). The Prompt of Using KIT IPA Toward Students Achievement on Science in Term of Scientific Attitude. Proceeding International Seminar on Education, Innovation Issues and Challenges in Education for Education Sustainability. Universitas Sarjanawiyata Tamansiswa. Yogyakarta.

Saputri, A.C., Sajidan, \& Rinanto, Y. (2017). Identifikasi keterampilan berpikir kritis siswa dalam pembelajaran biologi menggunakan window shopping. Prosiding Seminar Nasional Pendidikan Sains (SNPS). 131-135.

Subekti, Y. dan Ariswan.A. (2016). Pembelajaran Fisika dengan Metode Eksperimen untuk Meningkatkan Hasil Belajar kognitif dan Keterampilan Proses Sains. Jurnal Inovasi Pendidikan IPA, 2 (2). https://doi.org/10.21831/jipi.v2i2.6278

Suparno, P. (2007). Metodologi Pembelajaran Fisika Konstruktivisme dan Menyenangkan. Universitas Sanata Dharma Press. Yogyakarta. 